\title{
Short-course antibiotic treatment in acute exacerbations of chronic bronchitis and COPD: a meta-analysis of double-blind studies
}

\author{
R El Moussaoui, ${ }^{1}$ B M Roede, ${ }^{1}$ P Speelman, ${ }^{1}$ P Bresser, ${ }^{2} \mathrm{~J}$ M Prins, ${ }^{1}$ P M M Bossuyt ${ }^{3}$
}

See Editorial, p 390

${ }^{1}$ Department of Internal Medicine, Division of Infectious Diseases, Tropical Medicine and AIDS and Center for Infection and Immunity Amsterdam (CINIMA), Amsterdam, The Netherlands; ${ }^{2}$ Department of Pulmonology, Academic Medical Center, Amsterdam, The Netherlands; ${ }^{3}$ Department of Clinical Epidemiology and Biostatistics, Academic Medical Center, Amsterdam, The Netherlands

Correspondence to: Dr B M Roede, Academic Medical Center, University of Amsterdam, Department of Internal Medicine, Division of Infectious Diseases, Tropical Medicine and AIDS, Room F4217, Meibergdreef 9, 1105 AZ Amsterdam, The Netherlands; i.roede@amc.uva.nl

Received 14 September 2007 Accepted 16 December 2007 Published Online First 30 January 2008

\begin{abstract}
Background: A study was undertaken to determine whether a short course of antibiotic treatment ( $\leqslant 5$ days) is as effective as the conventional longer treatment in acute exacerbations of chronic bronchitis and chronic obstructive pulmonary disease (COPD).
\end{abstract}

Methods: MEDLINE, EMBASE and the Cochrane central register of controlled trials were searched to July 2006. Studies considered eligible were double-blind randomised clinical trials including adult patients $\geqslant 18$ years of age with a clinical diagnosis of exacerbation of COPD or chronic bronchitis, no antimicrobial therapy at the time of diagnosis and random assignment to antibiotic treatment for $\leqslant 5$ days versus $>5$ days. The primary outcome measure was clinical cure at early follow-up on an intention-to-treat basis.

Results: 21 studies with a total of 10698 patients were included. The average quality of the studies was high: the mean (SD) Jadad score was 3.9 (0.9). At early follow-up $(<25$ days), the summary odds ratio (OR) for clinical cure with short treatment versus conventional treatment was 0.99 (95\% Cl 0.90 to 1.08). At late follow-up the summary OR was $1.0(95 \% \mathrm{Cl} 0.91$ to 1.10$)$ and the summary OR for bacteriological cure was $1.05(95 \% \mathrm{Cl}$ 0.87 to 1.26 ). Similar summary ORs were observed for early cure in trials with the same antibiotic in both arms and in studies grouped by the antibiotic class used in the short-course arm.

Conclusions: A short course of antibiotic treatment is as effective as the traditional longer treatment in patients with mild to moderate exacerbations of chronic bronchitis and COPD.

Chronic bronchitis is one of the five leading causes of death worldwide and affects $3-17 \%$ of the adult population in developed countries. ${ }^{1}$ Acute exacerbations of chronic bronchitis and chronic obstructive pulmonary disease (COPD) occur frequently. Causes include air pollutants, allergens and viruses, as well as bacterial pathogens. The predominant bacterial pathogen implicated in acute exacerbations of chronic bronchitis and COPD is Haemophilus influenzae, which is present in $50 \%$ of all bacterial exacerbations, with approximately a further one-third of isolates being either Streptococcus pneumoniae or Moraxella catarrhalis. ${ }^{2}$

Most patients with acute exacerbations of chronic bronchitis and COPD are treated with antibiotics, but the benefit of antibiotic therapy remains controversial. This controversy is fuelled by data suggesting that at least one-third of exacerbations are non-infectious in origin. ${ }^{3-5}$ In addition, clinical trials of antibiotics have yielded conflicting data, with several large studies failing to demonstrate superiority of antibiotic therapy over placebo. ${ }^{67}$ Other trials indicated that antibiotic therapy is effective in patients who have at least two of the following symptoms: increased dyspnoea, increased sputum volume and increased sputum purulence (ie, a type 1 or 2 exacerbation), ${ }^{8}$ and in those with more severe airflow obstruction. ${ }^{9}$ A meta-analysis recently included in the Cochrane Library confirms these findings by demonstrating that, in acute exacerbations of chronic bronchitis and COPD with increased cough and sputum purulence, the use of antibiotics reduces the risk of short-term mortality by $77 \%$ and decreases the risk of treatment failure by $53 \% .^{10}$

This raises the question of how long the duration of antibiotic therapy should be. Antibiotic consumption in acute exacerbations of chronic bronchitis and COPD occurs on large scale and this may contribute to increasing resistance rates of the relevant pathogens. ${ }^{11}{ }^{12} \mathrm{Up}$ to $27 \%$ of $H$ influenzae and $>90 \%$ of $M$ catarrhalis produce $\beta$ lactamases, with large geographical differences. ${ }^{13}{ }^{14}$ Worldwide, the overall prevalence of penicillin non-susceptibility among strains of $S$ pneumoniae is around $30-40 \%$, with geographical variations between $2 \%$ and $60 \% .{ }^{15-17}$ The geographical differences can at least in part be attributed to differences in overall antibiotic consumption. ${ }^{12}$ A shorter duration of treatment might help contain these growing resistance rates, but shorter treatment can only be recommended if this is equally efficacious.

We performed a systematic review and metaanalysis of published randomised double-blind studies to determine whether a short course of antibiotic treatment is as effective as a long course in patients with a type 1 or 2 exacerbation of COPD/chronic bronchitis.

\section{METHODS}

Criteria for considering studies for this review and primary outcomes

Studies considered eligible for inclusion were randomised trials of antibiotic intervention involving adult patients $\geqslant 18$ years of age with a diagnosis of COPD or chronic bronchitis. Studies not published in the English language were excluded.

The primary outcome was clinical cure at early follow-up (as defined by the authors of the studies), defined as resolution or improvement of the clinical symptoms of the exacerbation. Treatment failure included lack of clinical resolution or 
improvement and indeterminate outcome: clinical response to the study drug could not be assessed for any reason. Secondary outcomes were: (1) the rate of clinical cure reported from the time of diagnosis to the final evaluation point (late follow-up): treatment failures included recurrences, relapses and indeterminate cases; and (2) the bacteriological cure rate. Bacteriological failure included persistence of the causative pathogen, presumed persistence (if no material was available for culture in a patient considered a clinical failure), and indeterminate outcome (if the bacteriological response to the study drug was not evaluable for any reason).

\section{Search strategy for identification of studies}

We searched the Cochrane central register of controlled trials on the Cochrane Library (Issue 2, 2006), Medline (1966-July 2006) and Embase (1988-July 2006) using the following search terms: chronic bronchitis or COPD, antibiotic treatment and clinical trials (see appendix A for details of the search strategy). We also searched the reference lists of included studies for additional studies.

\section{Data extraction}

Studies were included in the meta-analysis if they satisfied the following criteria: (1) adult patients $\geqslant 18$ years of age; (2) clinical diagnosis of exacerbation of COPD, chronic bronchitis or pulmonary emphysema; (3) no antimicrobial therapy at the time of diagnosis; (4) random assignment to antibiotic treatment for $\leqslant 5$ days versus treatment for $>5$ days; (5) study design with double blinding. Double-blind studies with azithromycin in the short arm were excluded. This antibiotic has a very long half-life and 3 days of treatment with azithromycin can therefore not be regarded as a short therapy.

Two authors independently rated abstracts identified by the electronic searches for inclusion in the meta-analysis. Inter-rater reliability for trial selection was assessed with Cohen's $\kappa$. In cases of disagreement between raters, the full original article was retrieved for data extraction. Differences in opinion over inclusion of studies were resolved through discussions and consensus.

Hard copies of the full article of all potentially eligible studies were obtained. Two reviewers independently extracted the following data from each study: author, year of publication, sample size, mean age of subjects, percentage of smokers, hospitalised or outpatient status of the subjects, antibiotic regimen used, antibiotic treatment duration, criteria used to define exacerbation of chronic bronchitis or COPD and the major outcome measure(s) for each study.

\section{Assessment of study quality}

The internal validity of included trials was assessed by the same reviewers using the Jadad scale. ${ }^{18}$ The scale assigns scores from 0 to 5 (best quality trial) based on the following items: (1) the study is randomised; (2) the intervention is double blind; (3) an accounting and description of study withdrawals is done; (4) the randomisation procedure is adequately performed using an appropriate method such as computer generated random numbers; and (5) the blindness is also adequately performed using identical-looking placebo.

Concealment of treatment allocation was also evaluated for adequacy: if trialists were unaware of each participant's

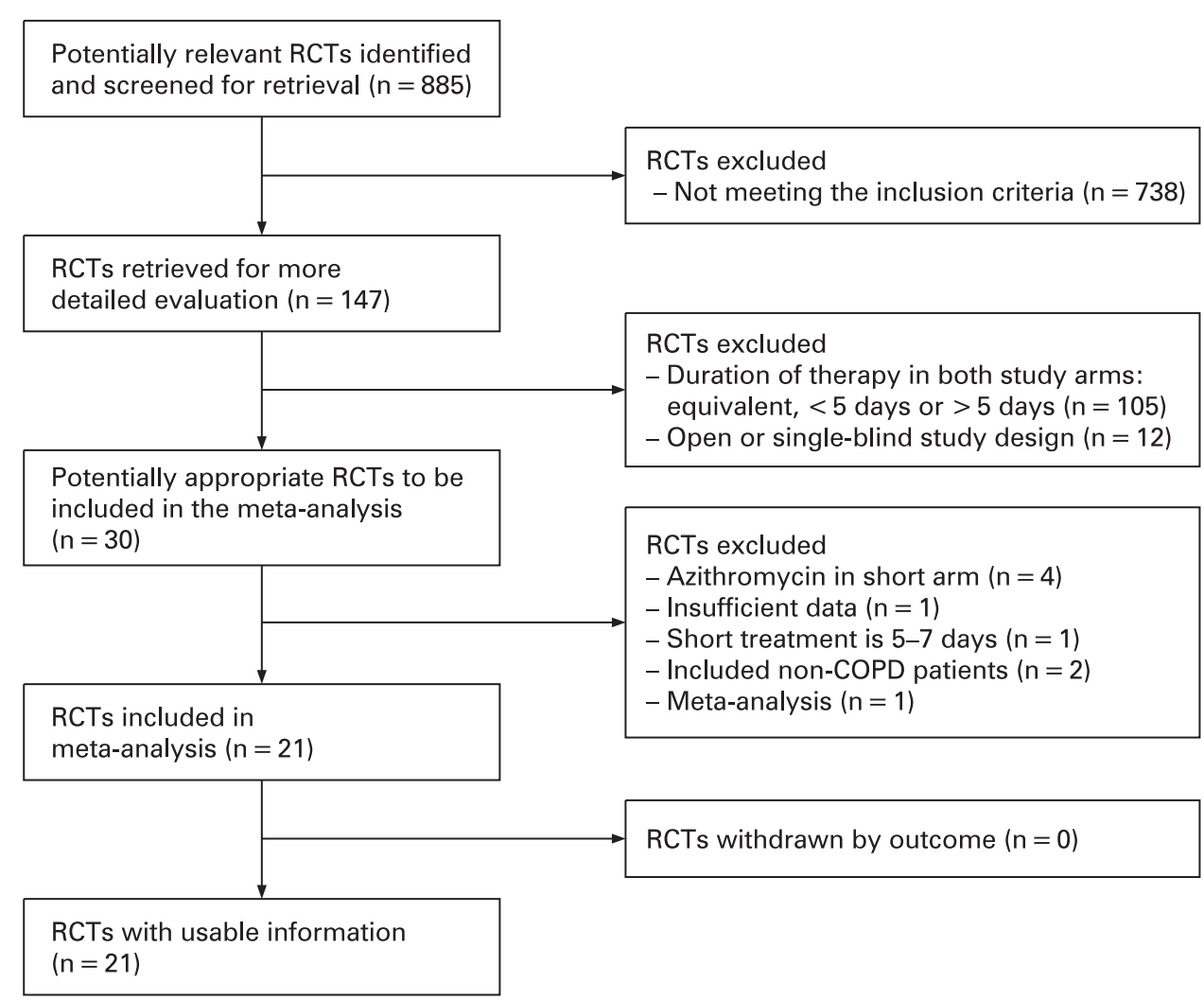

Figure 1 Flow diagram of stages in the systematic review of shorter duration antibiotic therapy in exacerbations of chronic obstructive pulmonary disease (COPD) or chronic bronchitis. RCT, randomised clinical trial. 
Table 1 Details of studies comparing short antibiotic treatment with conventional treatment (7-10 days) in patients with acute exacerbations of chronic bronchitis and COPD

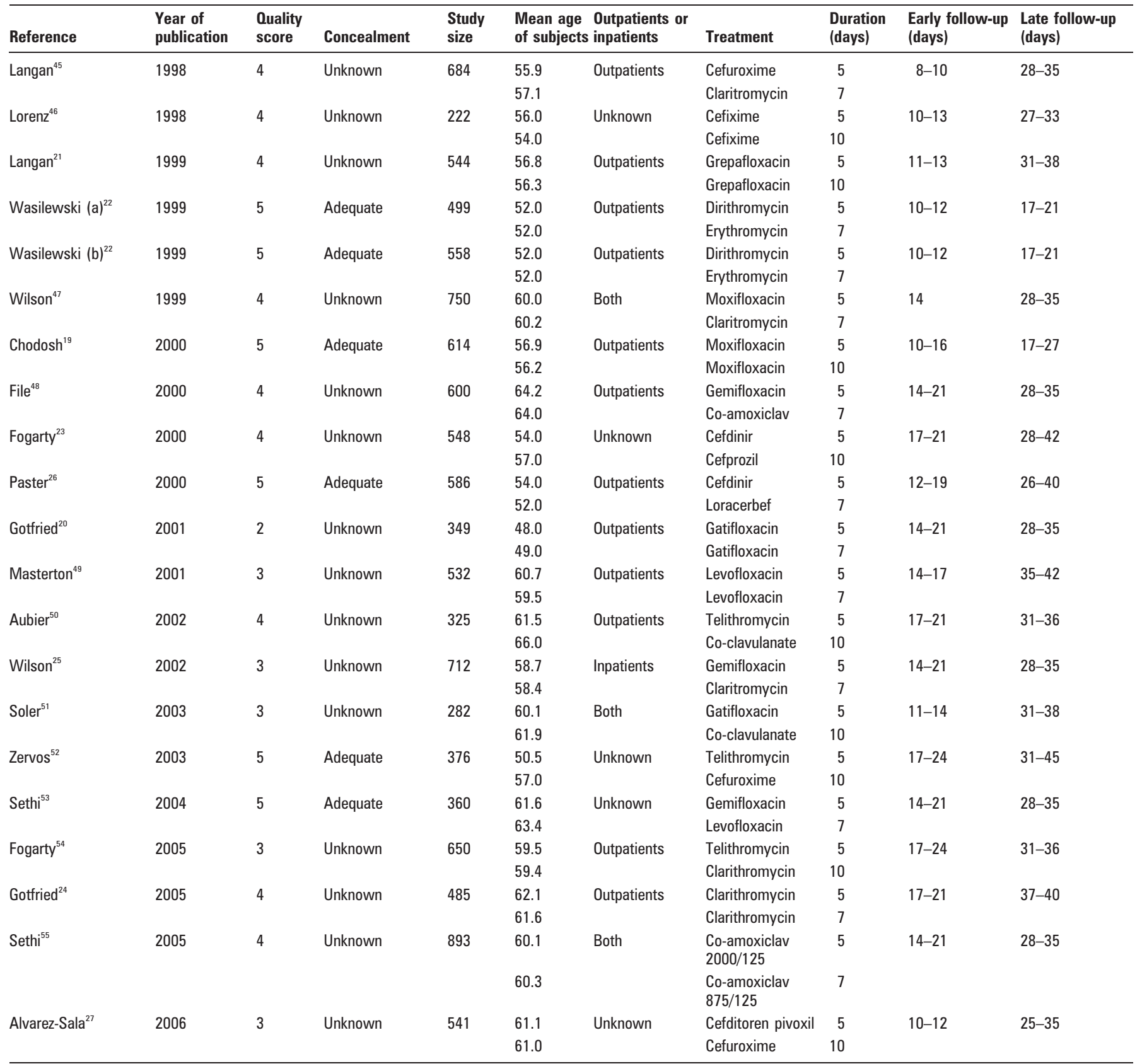

allocation when they were recruited, the allocation was said to be adequately concealed.

\section{Statistical analysis}

Meta-analyses were performed with the Cochrane collaboration's Revman 4.1 program (Cochrane Collaboration, Oxford, UK). From each study the clinical and bacterial cure rates were calculated and the chance of cure with a short course of antibiotics ( $\leqslant 5$ days) compared with a longer course ( $>5$ days) was expressed as an odds ratio (OR) with $95 \%$ confidence intervals (CIs). An OR of $<1$ indicates a lower number of cured cases with the short course of antibiotics and superiority of the long course of antibiotics.

Summary ORs were calculated based on the individual trial outcomes using the fixed-effect model. In additional analyses, studies were grouped by the class of antibiotic used in the short-course arm: cephalosporins, macrolides (other than azithromycin) and fluoroquinolones. Statistical heterogeneity among trials was assessed by $\chi^{2}$ analysis. The presence of publication bias was assessed by a funnel plot.

Sensitivity analyses were conducted to assess the robustness of the study by comparing summary ORs among groups redefined by (1) excluding trials of a lower methodological quality (Jadad score <4); (2) excluding trials with inadequate or unknown concealment; and (3) excluding trials of comparisons between different antibiotics.

\section{RESULTS}

\section{Literature search and trial inclusion}

The search strategy identified 885 studies. A total of 30 full hard copies were selected for further data extraction (fig 1). There was $94 \%$ agreement about which abstracts to include for retrieval of hard copies ( $\kappa=0.79,95 \%$ CI 0.66 to 0.92 ). 


\begin{tabular}{|c|c|c|c|c|c|}
\hline Study & $\begin{array}{c}\text { Short course } \\
n / N\end{array}$ & $\begin{array}{c}\text { Conventional course } \\
n / N\end{array}$ & $\begin{array}{c}\text { OR } \\
(95 \% \mathrm{Cl} \text { fixed })\end{array}$ & $\begin{array}{l}\text { Weight } \\
\%\end{array}$ & $\begin{array}{c}\text { OR } \\
\text { (95\% Cl fixed) }\end{array}$ \\
\hline Alvarez-Sala 2006 & $211 / 264$ & $229 / 277$ & $\longrightarrow$ & 5.2 & $0.83(0.54,1.29)$ \\
\hline Chodosh 2000 & $274 / 288$ & $266 / 281$ & & 1.5 & $1.10(0.52,2.33)$ \\
\hline File 2000 & $247 / 304$ & $247 / 296$ & $\rightarrow-$ & 5.4 & $0.86(0.56,1.31)$ \\
\hline Fogarty 2000 & $217 / 278$ & $200 / 270$ & & 5.1 & $1.25(0.84,1.85)$ \\
\hline Langan 1998 & $279 / 340$ & $281 / 344$ & & 5.8 & $1.03(0.69,1.51)$ \\
\hline Langan 1999 & $141 / 273$ & $149 / 268$ & $\rightarrow$ & 8.4 & $0.85(0.61,1.20)$ \\
\hline Lorenz 1998 & $77 / 108$ & 73/109 & - & 2.4 & $1.22(0.69,2.18)$ \\
\hline Masterton 2001 & $197 / 268$ & $207 / 262$ & 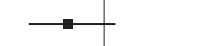 & 6.4 & $0.74(0.49,1.10)$ \\
\hline Paster 2000 & $138 / 291$ & $141 / 295$ & & 8.5 & $0.99(0.71,1.36)$ \\
\hline Wasilewski 1999B & $219 / 282$ & $206 / 276$ & & 5.3 & $1.18(0.80,1.74)$ \\
\hline Wilson 1999 & $287 / 374$ & $289 / 371$ & $\rightarrow$ & 7.8 & $0.94(0.66,1.32)$ \\
\hline Wilson 2002 & $279 / 351$ & $280 / 358$ & 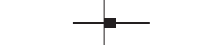 & 6.5 & $1.08(0.75,1.55)$ \\
\hline Zervos 2003 & $121 / 181$ & $138 / 191$ & $\longrightarrow$ & 5.2 & $0.76(0.49,1.18)$ \\
\hline Total $(95 \% \mathrm{Cl})$ & $4060 / 5261$ & $4078 / 5270$ & $\diamond$ & 100.0 & $0.99(0.90,1.08)$ \\
\hline \multicolumn{6}{|c|}{ Test for heterogeneity: $\chi^{2}=13.74, d f=19, p=0.8$} \\
\hline \multicolumn{6}{|c|}{ Test for overall effect $z=-0.28, p=0.8$} \\
\hline & & $\begin{array}{ll}1 & 1 \\
0.1 & 0.2\end{array}$ & 1 & $\begin{array}{ll} & 1 \\
5 & 10\end{array}$ & \\
\hline
\end{tabular}

Figure 2 Clinical cure at early follow-up.

Of these potentially eligible studies, 21 met the criteria for inclusion in the meta-analysis. Details of studies comparing short antibiotic treatment with conventional treatment (710 days) in patients with acute exacerbations of chronic bronchitis and COPD are shown in table 1.

Three trials had three treatment arms. ${ }^{19-21}$ In these cases the comparison of the short and long duration with the same antibiotic was chosen above the comparison between different antibiotics. Two trials were reported in a single paper. ${ }^{22}$ As sufficient information could be extracted from this paper, they were included in the meta-analysis.

\section{Methodological quality}

The mean (SD) quality score for the trials was $3.9(0.9)$ on the Jadad scale; $71 \%$ were of very high quality (Jadad score $\geqslant 4$; table 1). Substantial inter-rater agreement for assignment of this score was reached ( $\kappa=0.75,95 \%$ CI 0.60 to 0.90$)$. Seventeen studies $(81 \%)$ described the reasons for patient withdrawal. Six

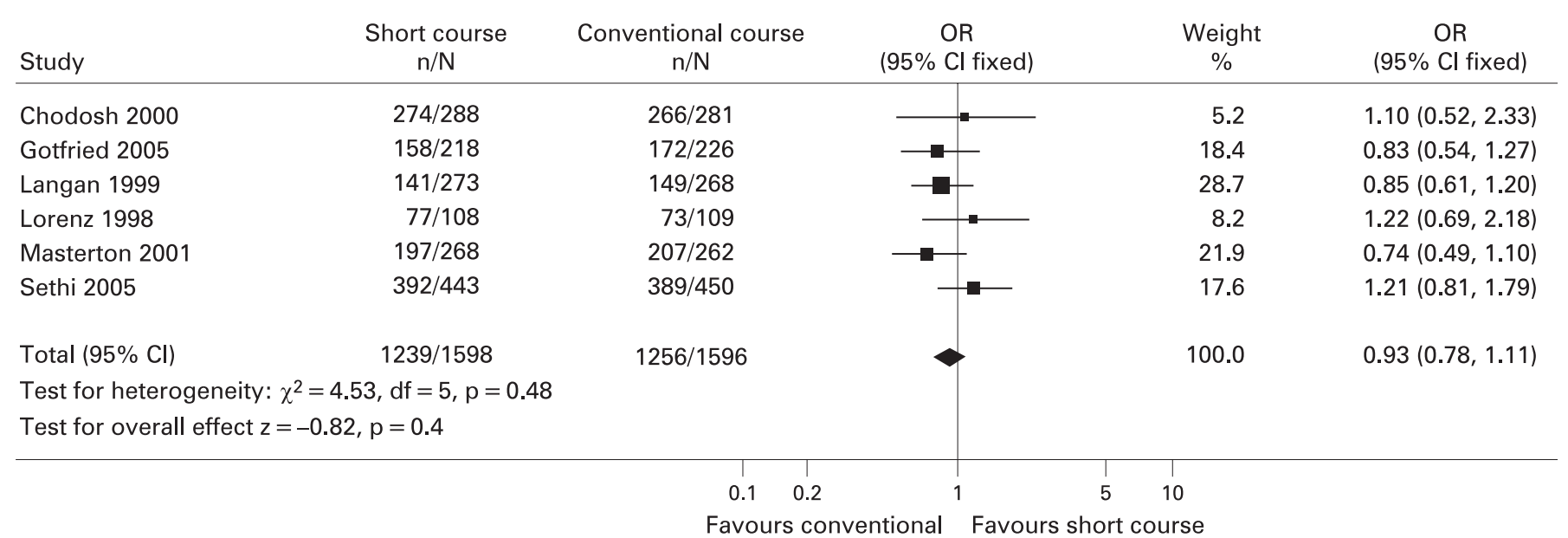

Figure 3 Clinical cure at early follow-up in trials with the same antibiotics in both study arms. 


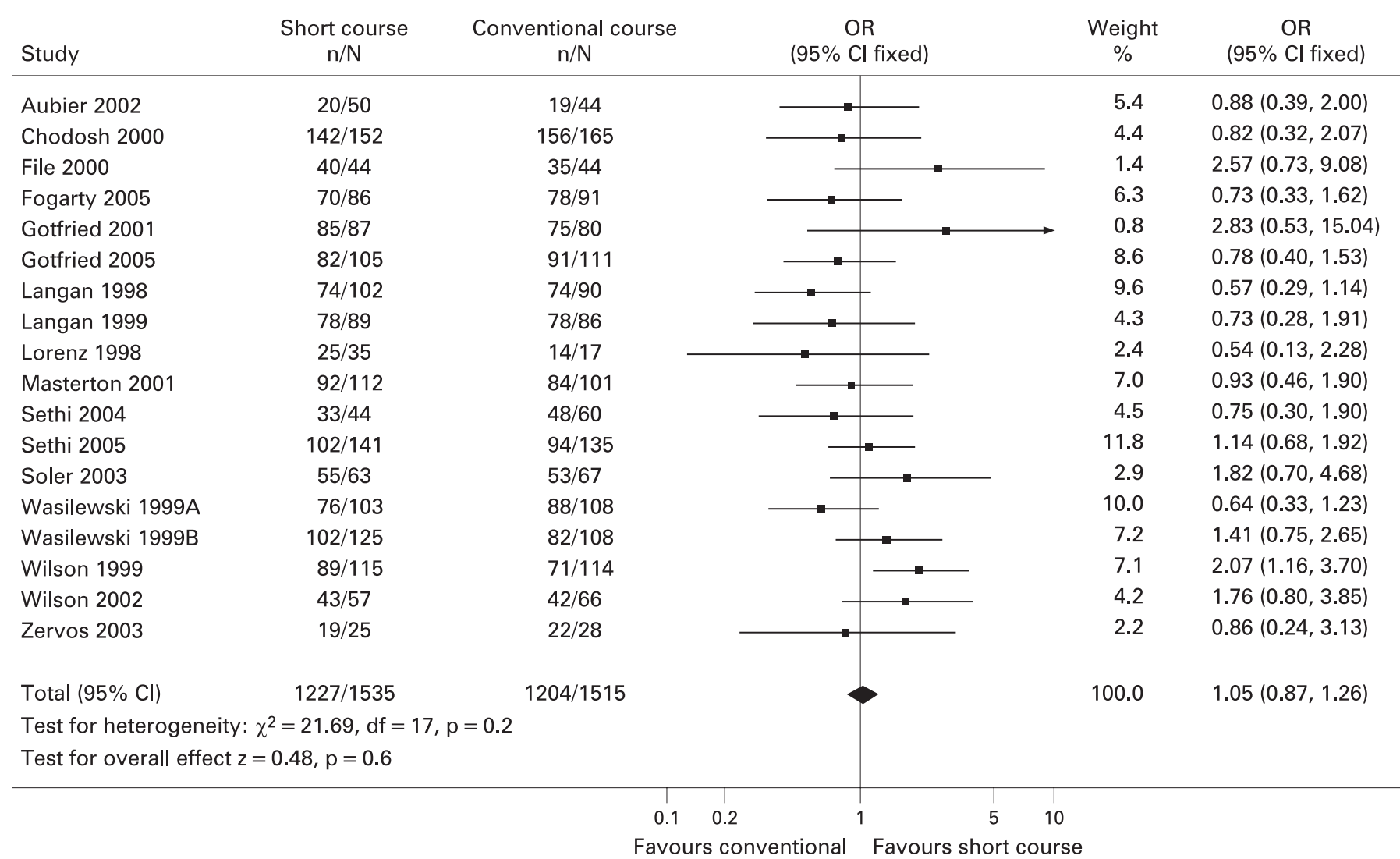

Figure 4 Bacteriological cure at early follow-up.

trials (29\%) were judged as having adequate allocation concealment (table 1); the remaining studies did not describe the concealment of treatment allocation.

\section{Description of trials}

The 21 included studies included a total of 10698 patients (table 1), of which 5348 patients were allocated to short treatment groups and 5350 to long treatment groups. Four trials did not specify how exacerbation was defined. ${ }^{20-22}$ All other trials included only patients satisfying at least two of the following criteria: increased cough and/or dyspnoea, increased sputum volume and increased purulence (ie, a type 1 or 2 exacerbation as defined by Anthonisen et $a l^{8}$ ). The mean (SD) age of study patients was 57.4 (4.3) years in the short treatment groups and 58 (4.4) years in the long treatment groups. The mean (SD) percentage of smokers in the short treatment and long treatment groups was $71.8(16.3) \%$ and $71.8(16.3) \%$, respectively. Most of the studies included outpatients. The mean (SD) duration of treatment was 4.9 (0.4) days in the short treatment groups and 8.3 (1.5) days in the long treatment groups (table 1).

All trials defined clinical cure as the disappearance of acute exacerbations of chronic bronchitis and COPD-related signs and symptoms, return to the pre-infection state, or sufficient improvement such that additional or alternative antimicrobial therapy was not required. The mean (SD) time of early followup evaluation was after 15 (3.5) days and the mean (SD) time of late evaluation was at day 31 (5.3). In all but one trial clinical cure rates at early follow-up could be extracted or calculated. ${ }^{20}$ Four studies did not report clinical cure rates at late follow-up. ${ }^{20} 23-25$ Three studies did not report bacteriological cure rates. ${ }^{23} 2627$

\section{Outcome of clinical and bacteriological cure rates}

The primary outcome analysed was the clinical cure rate at early follow-up in an intention-to-treat (ITT) analysis. Early follow-up was before day 25 in all studies. Tests for statistical heterogeneity were performed for all analyses. Statistically significant heterogeneity was not observed in the primary outcome of early clinical cure $(p=0.8)$ or in the secondary outcomes of late clinical cure $(p=0.34)$ and bacteriological cure $(p=0.2)$. A funnel plot did not suggest any form of publication bias.

The summary OR for early treatment cure was 0.99 (95\% CI 0.90 to 1.08 ) (fig 2). In trials with the same antibiotic in both arms, the summary OR was 0.93 (95\% CI 0.78 to 1.11) (fig 3). The summary OR for cured cases at late follow-up was $1.0(95 \%$ CI 0.91 to 1.10) and for bacteriological cure was 1.05 (95\% CI 0.87 to 1.26 ) (fig 4 ).

Similar summary ORs were observed for early clinical cure in studies grouped by the antibiotic class used in the short arm. The summary OR was 1.04 (95\% CI 0.87 to 1.24) for cephalosporins, 0.96 (95\% CI 0.80 to 1.16$)$ for macrolides and 0.94 (95\% CI 0.81 to 1.09) for fluoroquinolones (fig 5).

\section{Sensitivity analysis}

Sensitivity analyses were conducted for the primary outcome (ie, clinical cure rate at the early follow-up). Treatment cure rates were not significantly more likely with shorter duration in very high quality trials (summary OR 1.02, 95\% CI 0.91 to 1.13), 


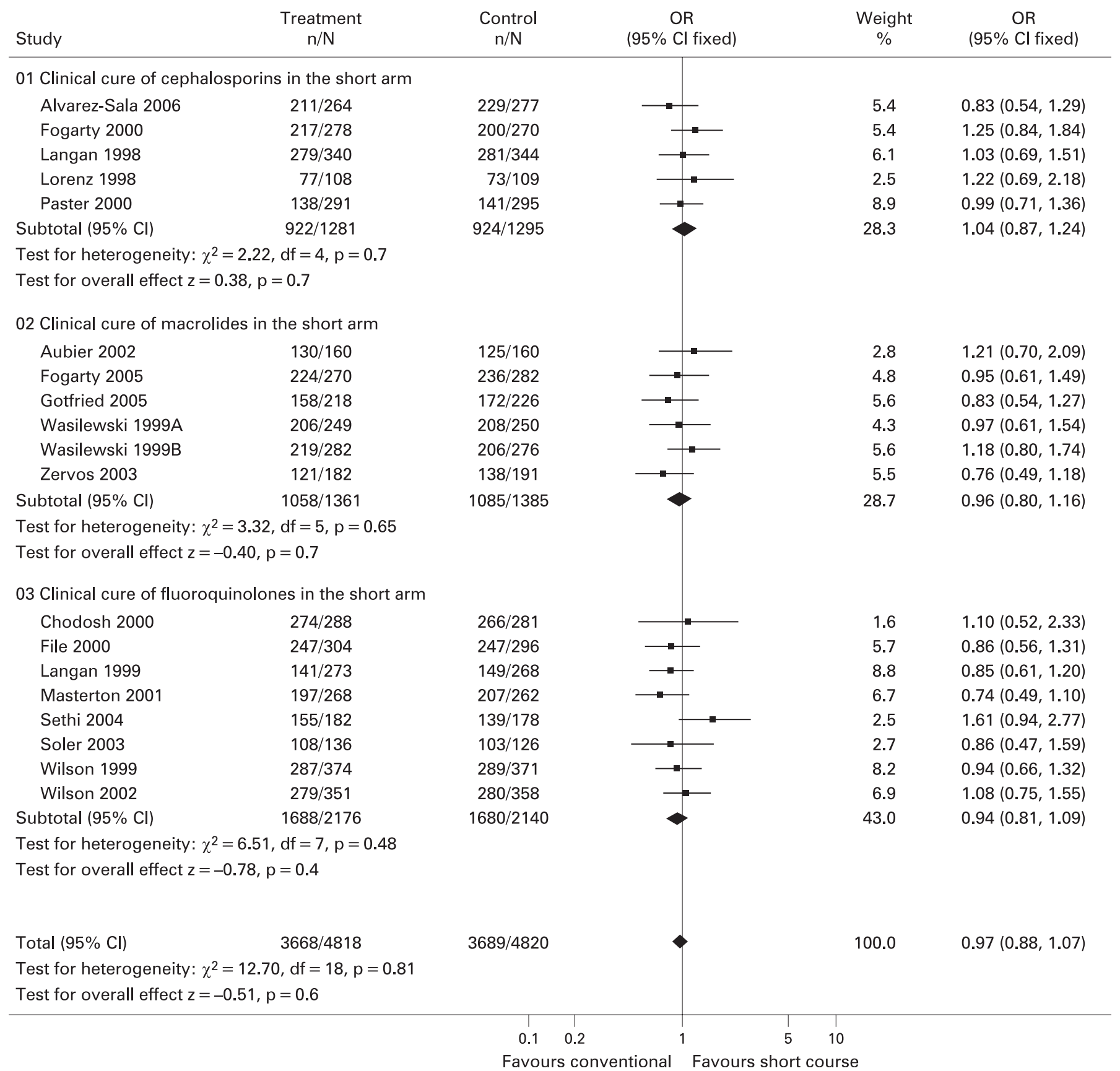

Figure 5 Clinical cure at early follow-up of studies grouped by antibiotic class.

trials with adequate concealment (summary OR 1.04, 95\% CI 0.87 to 1.24 ) or in trials with the same antibiotic in both arms (summary OR $0.93,95 \%$ CI 0.78 to 1.11 ).

\section{DISCUSSION}

In this systematic review of randomised double-blind studies we found that short courses of antibiotic therapy ( $\leqslant 5$ days) are as effective as the conventional courses of $>5$ days in the treatment of mild to moderate acute exacerbations of chronic bronchitis and COPD. The clinical cure rates at both early and late follow-up as well as the bacteriological cure rates were comparable for both treatment strategies. Similar summary ORs were found for early cure in trials with the same antibiotic in both arms.
The overall methodological quality of studies in our systematic review was found to be high or very high, with $71 \%$ of the studies having a Jadad score of at least 4 . Sensitivity analyses showed no differences between both treatment groups, enhancing the statistical robustness of the overall analysis and strengthening the appropriateness of combining all studies into a single meta-analysis. Statistically significant heterogeneity was not present.

A potential weakness of meta-analyses is the incorporation of existing biases and the introduction of new biases. ${ }^{28-30}$ To minimise bias during trial selection we used predetermined inclusion criteria. Language bias must be considered since this meta-analysis included only trials published in the English language. No signs of publication bias were detected. 
Different antibiotic classes are represented, but new agents were often used in the short treatment arm. Studying amoxicillin-clavulanic acid (co-amoxiclav) and tetracycline/ doxycycline in the short arm would be relevant. However, on microbiological or pharmacological grounds, there are no reasons to believe the results are different for these agents. Most of the studies included in the meta-analysis were conducted in the community, although at least four studies also included hospital inpatients. Although almost all exacerbations were classified as Anthonisen type 1 or 2, we feel some caution is necessary when applying our findings to patients with severe exacerbations who are admitted to hospital with respiratory failure.

Antibiotics are widely prescribed for respiratory tract infections, which account for $75 \%$ of community prescriptions. ${ }^{31}{ }^{32}$ Tonsillopharyngitis is the most frequent indication, followed by bronchitis. It has already been demonstrated that a short course (4-5 days) of treatment with a cephalosporin is at least as effective as 10 days of penicillin treatment in patients with group A streptococcal tonsillopharyngitis, ${ }^{33}$ and that a short course ( 5 days) of short-acting antibiotics is an effective treatment for uncomplicated acute otitis media in children. ${ }^{34}$ Studies investigating the effectiveness of shorter courses in community-acquired pneumonia show promising results. ${ }^{35-38}$

According to most guidelines on the treatment with COPD, antibiotic treatment is only indicated in patients with acute exacerbations of COPD characterised by increased sputum volume and purulence. ${ }^{3-5} 39$ The issue of the appropriate duration of antibiotic therapy, however, is not addressed in any of these guidelines.

Shorter courses of antibiotic treatment have several potential advantages compared with long courses of treatment. Poor compliance appears to be more common with longer treatment courses, so shorter courses of antibiotics may enhance compliance. The compliance rate in tonsillopharyngitis, in which penicillin therapy is typically prescribed for 10 days, is inversely related to the duration of treatment and has been observed to be as low as $8 \%$ by the ninth day of treatment. ${ }^{40-42}$ It is to be expected that a short course of treatment will also reduce antibiotic costs.

More important is the effect of unnecessarily lengthy courses on the development of resistant organisms. On a population level, there is a clear relationship between total antibiotic consumption and resistance rates of pathogens. ${ }^{11} 124344$ Decreasing the duration of antibiotic courses in respiratory tract infections might contribute to a decrease in these resistance rates. ${ }^{44}$

Our meta-analysis supports the effectiveness of short-course treatment in mild to moderate exacerbations of COPD or chronic bronchitis characterised by at least two of the following criteria: increased cough and/or dyspnoea, increased sputum volume and increased purulence. Based on the included studies, it seems that the duration of antibiotic treatment can be safely reduced. We therefore propose that the guidelines for COPD should recommend antibiotic treatment duration of no longer than 5 days, regardless of antibiotic class, in mild to moderate exacerbations of COPD or chronic bronchitis.

Acknowledgements: The authors thank Heleen C Dyserinck for her support with the search strategy.

Funding: Healthcare Insurance Board, Amstelveen, The Netherlands (grant OG99038).

\section{Competing interests: None.}

The sponsors of the study had no role in study design, data collection, data analysis, data interpretation or writing of the report. The corresponding author had full access to all the data in the study and had final responsibility for the decision to submit for publication.

\section{REFERENCES}

1. Ball $\mathbf{P}$, Make B. Acute exacerbations of chronic bronchitis: an international comparison. Chest 1998;113(3 Suppl):199-204S.

2. Ball P. Epidemiology and treatment of chronic bronchitis and its exacerbations. Chest 1995;108(2 Suppl):43-52S.

3. Bellamy D. The NICE COPD guidelines 2004: what are the messages for primary care? Prim Care Respir J 2004;13:84-8.

4. Celli BR, MacNee W. Standards for the diagnosis and treatment of patients with COPD: a summary of the ATS/ERS position paper. Eur Respir J 2004;23:932-6.

5. Global Initiative for Chronic Obstructive Lung Disease. Global strategy for the diagnosis, management, and prevention of COPD. Summary of GOLD recommendations with citations from the scientific literature. Revised 2006. http:// www.goldcopd.com/Guidelineitem.asp?!1 = 2ধl2 = 1 \&intld = 996 (accessed $13 \mathrm{Dec}$ 2007).

6. Elmes PC, King TK, Langlands JH, et al. Value of ampicillin in the hospital treatment of exacerbations of chronic bronchitis. BMJ 1965;904-8.

7. Nicotra MB, Rivera M, Awe RJ. Antibiotic therapy of acute exacerbations of chronic bronchitis. A controlled study using tetracycline. Ann Intern Med 1982;97:18-21.

8. Anthonisen NR, Manfreda J, Warren CP, et al. Antibiotic therapy in exacerbations of chronic obstructive pulmonary disease. Ann Intern Med 1987;106:196-204.

9. Saint S, Bent $S$, Vittinghoff $E$, et al. Antibiotics in chronic obstructive pulmonary disease exacerbations. A meta-analysis. JAMA 1995;273:957-60.

10. Ram FSF, Rodriguez RR, Granados NA, et al. Antibiotics for exacerbations of chronic obstructive pulmonary disease. Cochrane Database Syst Rev 2006;CD004403.

11. Bronzwaer SL, Cars 0, Buchholz U, et al. A European study on the relationship between antimicrobial use and antimicrobial resistance. Emerg Infect Dis 2002;8:278-82

12. Goossens H, Ferech M, Van der Stichele R, et al. Outpatient antibiotic use in Europe and association with resistance: a cross-national database study. Lancet 2005;365:579-87.

13. Critchley IA, Brown SD, Traczewski MM, et al. National and regional assessment of antimicrobial resistance among community-acquired respiratory tract pathogens identified in a 2005-2006 U.S. faropenem surveillance study. Antimicrob Agents Chemother 2007;51:4382-9.

14. Hoban D, Felmingham D. The PROTEKT surveillance study: antimicrobial susceptibility of Haemophilus influenzae and Moraxella catarrhalis from communityacquired respiratory tract infections. J Antimicrob Chemother 2002;50(Suppl S1):4959.

15. Morrissey I, Colclough A, Northwood J. TARGETed surveillance: susceptibility of Streptococcus pneumoniae isolated from community-acquired respiratory tract infections in 2003 to fluoroquinolones and other agents. Int J Antimicrob Agents 2007;30:345-51.

16. Cantón R, Unal S, Farrell DJ. Antibacterial resistance patterns in Streptococcus pneumoniae isolated from elderly patients: PROTEKT years 1-5 (1999-2004). Int J Antimicrob Agents 2007;30:546-50.

17. SWAB. NethMap 2007 - Consumption of antimicrobial agents and antimicrobial resistance among medically important bacteria in the Netherlands. http://www.swab.nl/swab/swabcms.nsf/(WebFiles)/ D552D3B6190D0461C12572FF0024F246/\$FILE/NETHMAP 2007.pdf laccessed 30 Nov 2007).

18. Moher D, Jadad AR, Nichol G, et al. Assessing the quality of randomized controlled trials: an annotated bibliography of scales and checklists. Control Clin Trials 1995; 16:62-73

19. Chodosh S, DeAbate CA, Haverstock D, et al. Short-course moxifloxacin therapy for treatment of acute bacterial exacerbations of chronic bronchitis. Respir Med 2000;94:18-27.

20. Gotfried MH, DeAbate CA, Fogarty C, et al. Comparison of 5-day, short-course gatifloxacin therapy with 7-day gatifloxacin therapy and 10-day clarithromycin therapy for acute exacerbation of chronic bronchitis. Clin Ther 2001;23:97-107.

21. Langan CE, Zuck P, Vogel F, et al. Randomized, double-blind study of short-course (5 day) grepafloxacin versus 10 day clarithromycin in patients with acute bacterial exacerbations of chronic bronchitis. J Antimicrob Chemother 1999;44:515-23.

22. Wasilewski MM, Johns D, Sides GD. Five-day dirithromycin therapy is as effective as seven-day erythromycin therapy for acute exacerbations of chronic bronchitis. J Antimicrob Chemother 1999;43:541-8.

23. Fogarty $\mathbf{C M}$, Bettis RB, Griffin TJ, et al. Comparison of a 5 day regimen of cefdinir with a 10 day regimen of cefprozil for treatment of acute exacerbations of chronic bronchitis. J Antimicrob Chemother 2000;45:851-8.

24. Gotfried M, Notario G, Spiller J, et al. Comparative efficacy of once daily, 5-day short-course therapy with clarithromycin extended-release versus twice daily, 7-day therapy with clarithromycin immediate-release in acute bacterial exacerbation of chronic bronchitis. Curr Med Res Opin 2005;21:245-54.

25. Wilson R, Schentag JJ, Ball P, et al. A comparison of gemifloxacin and clarithromycin in acute exacerbations of chronic bronchitis and long-term clinical outcomes. Clin Ther 2002;24:639-52.

26. Paster $\mathbf{R Z}$, McAdoo MA, Keyserling $\mathrm{CH}$, et al. A comparison of a five-day regimen of cefdinir with a seven-day regimen of loracarbef for the treatment of acute exacerbations of chronic bronchitis. Int J Clin Pract 2000;54:293-9. 
27. Alvarez-Sala JL, Kardos P, Martinez-Beltran J, et al. Clinical and bacteriological efficacy in treatment of acute exacerbations of chronic bronchitis with cefditorenpivoxil versus cefuroxime-axetil. Antimicrob Agents Chemother 2006;50:1762-7.

28. Egger M, Davey SG, Schneider M, et al. Bias in meta-analysis detected by a simple, graphical test. BMJ 1997;315:629-34.

29. Moher D, Pham B, Jones A, et al. Does quality of reports of randomised trials affect estimates of intervention efficacy reported in meta-analyses? Lancet 1998;352:609_ 13.

30. Moher D, Cook DJ, Eastwood S, et al. Improving the quality of reports of metaanalyses of randomised controlled trials: the QUOROM statement. Quality of Reporting of Meta-analyses. Lancet 1999;354:1896-900.

31. Carbon C, Bax RP. Regulating the use of antibiotics in the community. BMJ 1998;317:663-5.

32. Guillemot D, Maison $P$, Carbon $C$, et al. Trends in antimicrobial drug use in the community - France, 1981-1992. J Infect Dis 1998:177:492-7.

33. Casey JR, Pichichero ME. Metaanalysis of short course antibiotic treatment for group a streptococcal tonsillopharyngitis. Pediatr Infect Dis J 2005;24:909-17.

34. Kozyrskyj AL, Hildes-Ripstein GE, Longstaffe SE, et al. Treatment of acute otitis media with a shortened course of antibiotics: a meta-analysis. JAMA 1998:279:1736-42.

35. Pakistan Multicentre Amoxycillin Short Course Therapy (MASCOT) Pneumonia Study Group. Clinical efficacy of 3 days versus 5 days of ora amoxicillin for treatment of childhood pneumonia: a multicentre double-blind trial. Lancet 2002;360:835-41.

36. Agarwal G, Awasthi S, Kabra SK, et al. Three day versus five day treatment with amoxicillin for non-severe pneumonia in young children: a multicentre randomised controlled trial. BMJ 2004;328:791

37. Dunbar LM, Wunderink RG, Habib MP, et al. High-dose, short-course levofloxacin for community-acquired pneumonia: a new treatment paradigm. Clin Infect Dis 2003; 37:752-60.

38. El Moussaoui R, de Borgie CA, van den Broek PH, et al. Effectiveness of discontinuing antibiotic treatment after three days versus eight days in mild to moderate-severe community acquired pneumonia: randomised, double blind study. BMJ 2006:332:1355-62.

39. COPD Guidelines Group of the Standards of Care Committee of the BTS. BTS guidelines for the management of chronic obstructive pulmonary disease. Thorax 1997:52(Suppl 5):S1-28.

40. Bergman $\mathbf{A B}$, Werner RJ. Failure of children to receive penicillin by mouth N Engl J Med 1963;268:1334-8.

41. Pichichero ME, Cohen R. Shortened course of antibiotic therapy for acute otitis media, sinusitis and tonsillopharyngitis. Pediatr Infect Dis J 1997:16:680-95.

42. Pichichero ME, Casey JR, Mayes T, et al. Penicillin failure in streptococcal tonsillopharyngitis: causes and remedies. Pediatr Infect Dis J 2000;19:917-23.

43. Arason VA, Kristinsson KG, Sigurdsson JA, et al. Do antimicrobials increase the carriage rate of penicillin resistant pneumococci in children? Cross sectional prevalence study. BMJ 1996;313:387-91.

44. Seppala H, Klaukka T, Vuopio-Varkila J, et al. The effect of changes in the consumption of macrolide antibiotics on erythromycin resistance in group $A$ streptococci in Finland. Finnish Study Group for Antimicrobial Resistance. N Engl J Med 1997:337:441-6.

45. Langan C, Clecner B, Cazzola CM, et al. Short-course cefuroxime axetil therapy in the treatment of acute exacerbations of chronic bronchitis. Int J Clin Pract 1998;52:28997.

46. Lorenz J, Steinfeld P, Drath L, et al. Efficacy and tolerability of 5- vs 10-day cefixime therapy in acute exacerbations of chronic bronchitis. Clin Drug Investig 1998;15:1320.

47. Wilson R, Kubin R, Ballin I, et al. Five day moxifloxacin therapy compared with 7 day clarithromycin therapy for the treatment of acute exacerbations of chronic bronchitis. J Antimicrob Chemother 1999:44:501-13.

48. File T, Schlemmer B, Garau J, et al. Gemifloxacin versus amoxicillin/clavulanate in the treatment of acute exacerbations of chronic bronchitis. J Chemother 2000;12:314-25.
49. Masterton RG, Burley CJ. Randomized, double-blind study comparing 5- and 7-day regimens of oral levofloxacin in patients with acute exacerbation of chronic bronchitis. Int J Antimicrob Agents 2001;18:503-12.

50. Aubier M, Aldons PM, Leak A, et al. Telithromycin is as effective as amoxicillin/ clavulanate in acute exacerbations of chronic bronchitis. Respir Med 2002:96:862 71.

51. Soler M, Lode $\mathrm{H}$, Baldwin $\mathrm{R}$, et al. Randomised double-blind comparison of oral gatifloxacin and co-amoxiclav for acute exacerbation of chronic bronchitis. Eur J Clin Microbiol Infect Dis 2003;22:144-50.

52. Zervos MJ, Heyder AM, Leroy B. Oral telithromycin $800 \mathrm{mg}$ once daily for 5 days versus cefuroxime axetil $500 \mathrm{mg}$ twice daily for 10 days in adults with acute exacerbations of chronic bronchitis. J Int Med Res 2003:31:157-69.

53. Sethi S, Fogarty C, Fulambarker A. A randomized, double-blind study comparing 5 days oral gemifloxacin with 7 days oral levofloxacin in patients with acute exacerbation of chronic bronchitis. Respir Med 2004;98:697-707.

54. Fogarty C, de Wet R, Mandell $L$, et al. Five-day telithromycin once daily is as effective as 10-day clarithromycin twice daily for the treatment of acute exacerbations of chronic bronchitis and is associated with reduced health-care resource utilization. Chest 2005;128:1980-8.

55. Sethi S, Breton J, Wynne B. Efficacy and safety of pharmacokinetically enhanced amoxicillin-clavulanate at 2000/125 milligrams twice daily for 5 days versus amoxicillin-clavulanate at $875 / 125$ milligrams twice daily for 7 days in the treatment of acute exacerbations of chronic bronchitis. Antimicrob Agents Chemother $2005 \cdot \mathbf{4 9} \cdot 153-60$

\section{Appendix A}

Electronic search strategy using Medline:

(("Pulmonary Disease, Chronic Obstructive"[MeSH]) OR (chronic bronchitis) OR (pulmonary emphysema) OR (chronic obstructive bronchitis*) OR (chronic airflow limitation*) OR (chronic airflow obstruction*) OR (obstructive airways disease*) OR (chronic obstructive lung disease*)|

AND

(("Anti-Bacterial Agents"[MeSH] OR "Anti-Bacterial Agents"[Pharmacological Action]) OR (antibiotic*))

AND

([randomized controlled trial[pt] OR controlled clinical trial[pt] OR randomized controlled trials[mh] OR random allocation[mh] OR double-blind method[mh] OR single-blind method [mh] OR clinical trial[pt] OR clinical trials[mh] OR "clinical trial" [tw] OR ((singl*[tw] OR doubl*[tw] OR trebl*[tw] OR tripl*[tw])

AND

(mask*[tw] OR blind* [tw])) OR "latin square" [tw] OR placebos[mh] OR placebo*[tw] OR random*[tw] OR research design[mh:noexp] OR comparative study[mh] OR evaluation studies[mh] OR follow-up studies[mh] OR prospective studies[mh] OR cross-over studies[mh] OR control*[tw] OR prospectiv*[tw] OR volunteer*[tw]) NOT (animal[mh] NOT human[mh])) Limits: English

Electronic search strategy using Ovid

1. exp Chronic Obstructive Lung Disease/

2. exp Chronic Bronchitis/

3. exp lung emphysema/

4. chronic bronchitis.tw.

5. lung emphysema.tw.

6. chronic obstructive lung disease.tw.

7. pulmonary emphysema.tw

8. 1 or 2 or 3 or 4 or 5 or 6 or 7

9. exp Antibiotic Agent/

10. 8 and 9

11. random $\$$.tw.

12. 10 and 11

13. limit 12 to (human and English language) 